Portland State University

PDXScholar

\title{
Space-angle Signal Processing Using a Modulated Scatter Array
}

Nasr Alkhafaji

Portland State University

Follow this and additional works at: https://pdxscholar.library.pdx.edu/ece_phd_day

Part of the Electrical and Electronics Commons

Let us know how access to this document benefits you.

\section{Citation Details}

Alkhafaji, Nasr, "Space-angle Signal Processing Using a Modulated Scatter Array" (2018). Electrical and Computer Engineering PhD Day. 5.

https://pdxscholar.library.pdx.edu/ece_phd_day/5

This Poster is brought to you for free and open access. It has been accepted for inclusion in Electrical and Computer Engineering PhD Day by an authorized administrator of PDXScholar. Please contact us if we can make this document more accessible: pdxscholar@pdx.edu. 


\section{SPACE-ANGLE SIGNAL PROCESSING USING A MODULATED SCATTER ARRAY}

\section{PORTLAND STATE UNIVERSITY-ELECTRICAL ENGINEERING DEPARTMENT}

NASR ALKHAFAJI, RICHARD CAMPBELL, MADELEINE ROCHE

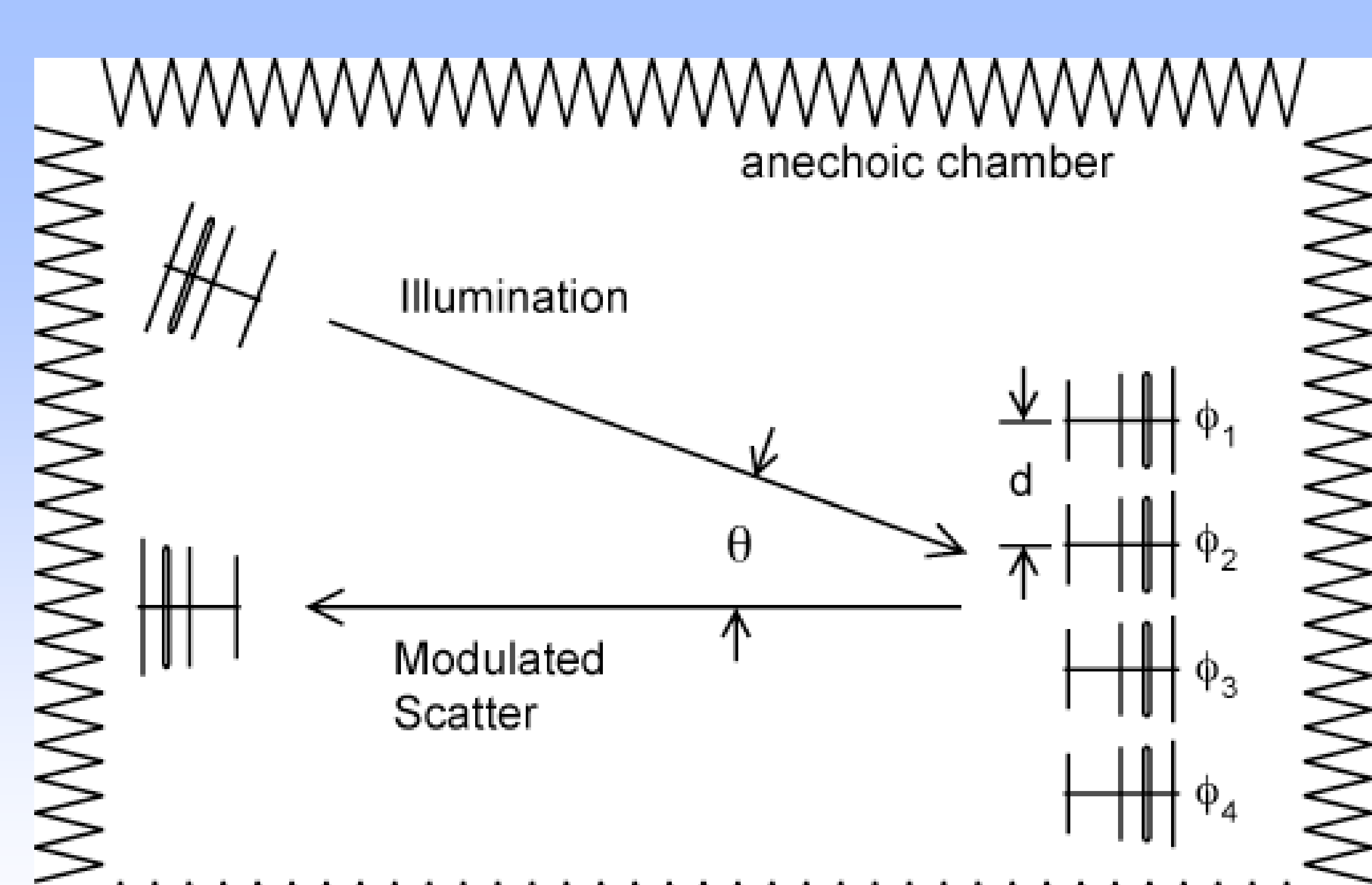

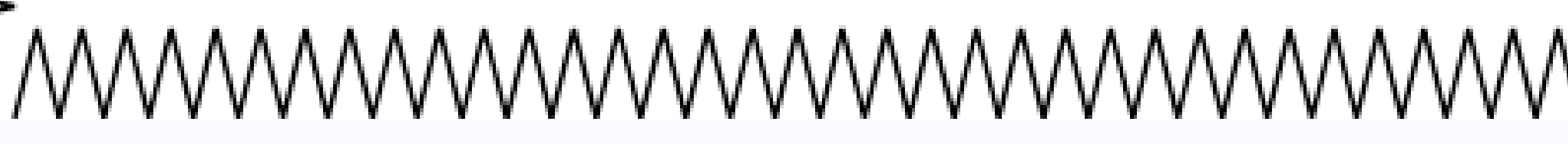

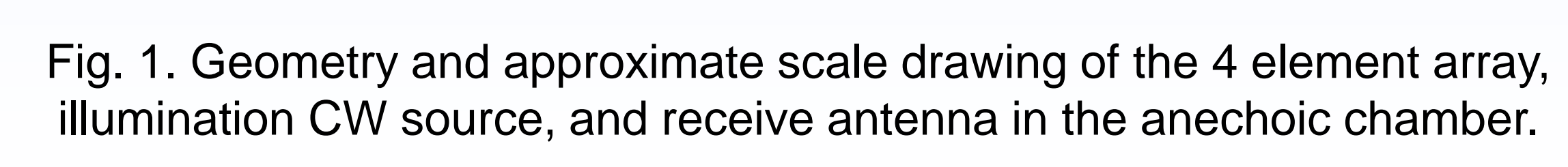

\section{Theoretical Background}

Spatial diversity-frequency diversity transformation is a process to assign an angular scattered beam in the space for each different frequency, requiring a multi-frequency generator and a multi antenna radiator (antenna) array. Referring to Figure 1, a CW signal at $432 \mathrm{MHz}$ illuminates the array, arriving at an angle $\Theta$. The relative distributed phase among antenna elements is related to element spacing $d$ and arrival angle $\Theta$. The induced signal will be modulated by $700 \mathrm{~Hz}$ sine wave signal at the RF diode switches, leading into intermodulation distortion generation IMD due to inherited nonlinearities in semiconductor devices.

$y(t)=a 1 x^{\wedge}(t)+a 2 x^{\wedge} 2(t)+a 3 x^{\wedge} 3(t)+a 4 x^{\wedge} 4(t)+\cdots$

The input signal consists of two tones the illuminated and the modulating signals, and the output signal will have the desire IMD ones and undesired products. Antenna array works to cancel or boost the specific frequency-angular scattered beam in the desired directions. The procedure of space-angle signal processing is illustrated by the help of the block diagram in Figure2. Figure 2 illustrates that more IMD products can be cancelled at a specific direction if we increase the No. of circuit paths (i.e. No. of antenna array elements). In the space angle domain, the undesired IMD products are not suppressed, it just reradiates at different angles. Figure 3 shows an array pattern with illumination angles labeled according to which modulation product adds in phase at the receiver. The center lobe is the backscatter direction.

\section{Abstract}

A UHF signal processing technique is described in the Fourier Space-Angle domain that uses an array of scattering elements with reflection coefficients modulated at baseband. The illumination arrival angle distributes a UHF phase across the array, and the baseband modulator phase at each of the array elements determines the radiation angle of the desired scattered product. Undesired products are re-radiated in different directions. Example 1, 2 and 4 element arrays operate at $432 \mathrm{MHz}$ array with $700 \mathrm{~Hz}$ modulation. 2 element arrays cancel one sideband, and the 4 element array cancels both the undesired sideband and 2 nd order products. Reflection coefficient modulation uses slow electronics, and scattered signals are summed in space, so this technique is attractive at much higher frequencies.

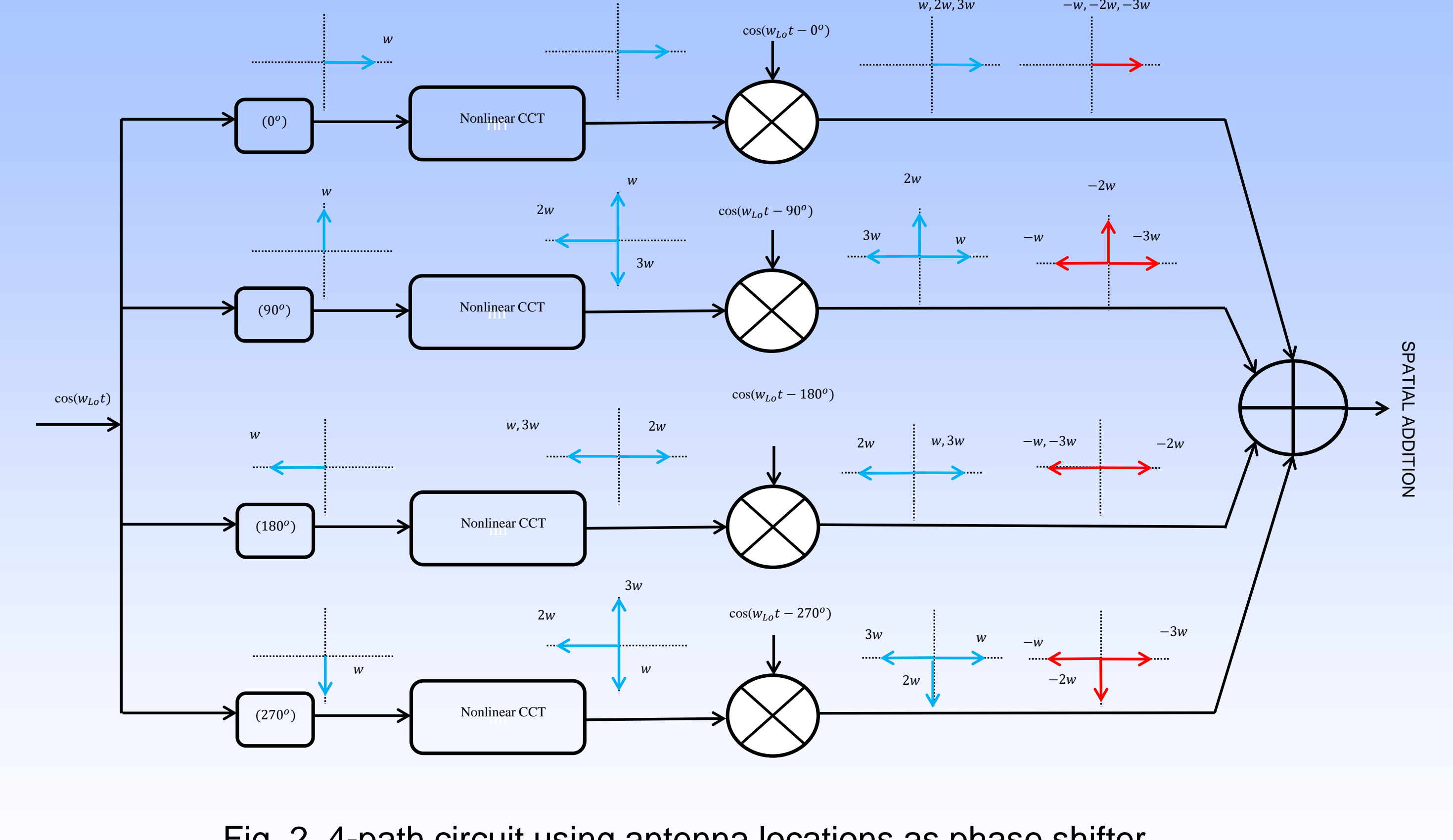

Fig. 2. 4-path circuit using antenna locations as phase shitter.

\section{Experimental setup \& Measured Results} Signals at the receive antenna in Figure 1 are converted to the 0 to $20 \mathrm{kHz}$ baseband output of an instrumentation receiver without automatic gain control and $100 \mathrm{~dB}$ noise floor to clipping level dynamic range. Figure 4 depicts the single diode modulator and the 4-element array scatter inside the anechoic chamber. Figures 5, 6 and 7 show the output spectrum plots of the received signals for a single scatter, a two element scatter, and a four element scatter respectively. The modulation sidebands are symmetrical around the down converted illuminating signal and harmonics of $700 \mathrm{~Hz}$ out to the $5^{\text {th }}$ are significant, as shown in Figure

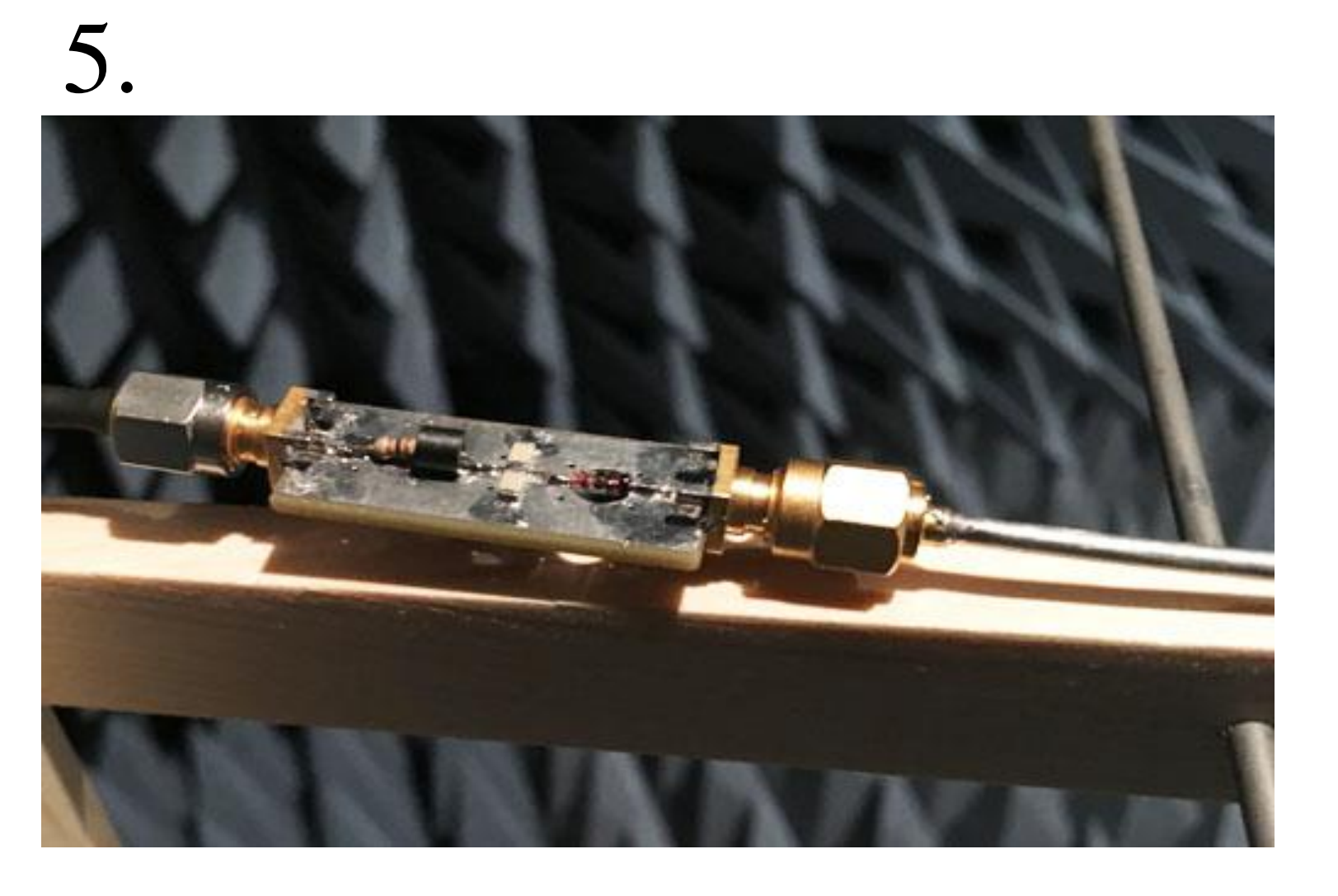

Fig. 4. single diode modulator, and 4-element modulation scatter array.

Figure 6 shows the received signal baseband spectrum from the 2 element array with 0 and 90 degree phase modulation. Note that the lower sideband is suppressed, but the lower third harmonic sideband is enhanced. Similarly, the upper third harmonic sideband is suppressed. This is expected, as the third harmonic phase is 270 degrees $(3 \times 90)$. Figure 7 shows measured suppression of the lower sideband and 2nd harmonic components. 2nd harmonic suppression occurs both above and below the $\mathrm{CW}$ illumination, as the second harmonic multiplication results in $0 \times 2,90 \times 2,180 \times 2$ and $270 \times 2$

products at the four array elements.
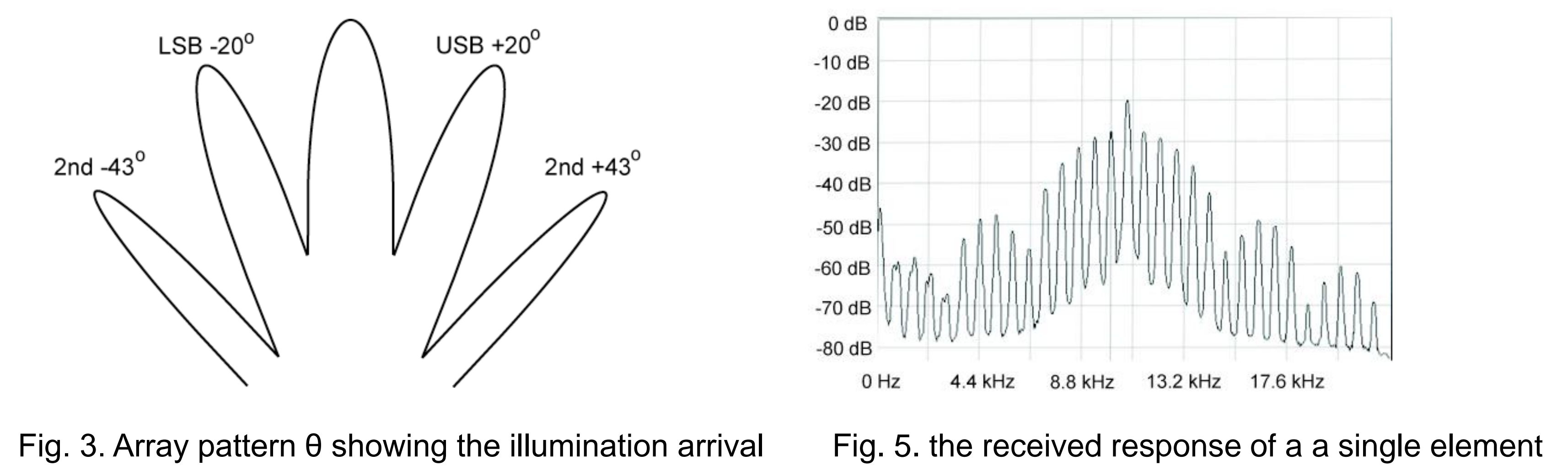

Fig. 3. Array pattern $\theta$ showing the illumination arriva angle that results in summation of the
upper and lower 2 2nd order products.
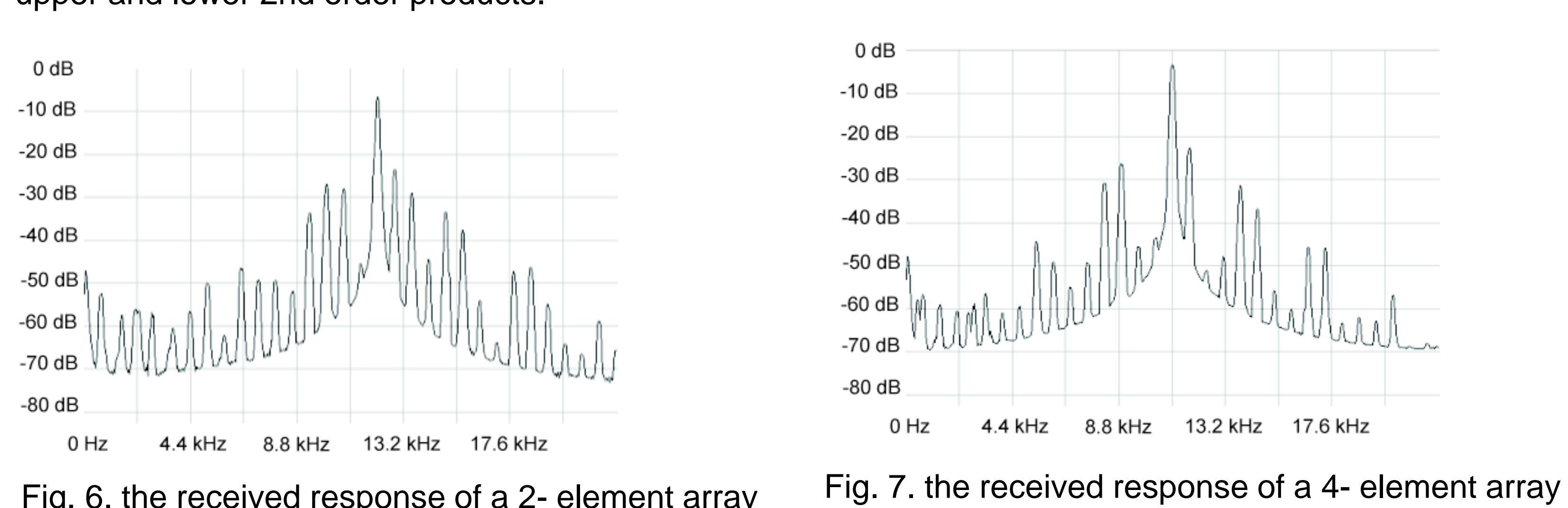

III. Conclusion

This necessarily brief treatment of early results with arrays of modulated scatters at UHF shows the practicality of this

concept. From basic Fourier Theory the advantages of arrays with more than 4 elements are evident, and our ongoing work is at higher frequencies where such arrays are practical in our anechoic chamber. The desired output signals are added in space,

without the need for electronics, waveguide, or transmission lines. IV. References

1. M. Roche, et al, "UHF Reflection Coefficient Modulator Array Element," IMS 2018, accepted.
N Alkhafaiji et al., "Space-Angle Signal Processing using a Modulated Scatter Array, IMS 2018 . 